\title{
Proposed Calibration of Apheresis Equipment
}

\author{
By A. A. dos Santos' ${ }^{1}$, M. A. Marciano' ${ }^{2}$ and R. L. Rezer ${ }^{1}$ \\ ${ }^{1}$ Hospital Moinhos de Vento/Clinical Engineering, Porto Alegre, Brazil \\ ${ }^{2}$ Hospital Moinhos de Vento/ Clinical and Hospital Engineering, Porto Alegre, Brazil
}

\begin{abstract}
The health establishment is currently developing quality control through the calibration of biomedical equipment, systematically and comprehensively throughout the wide range of available hospital technology. Thus, this work aims to propose and demonstrate a method of qualifying apheresis equipment through equipment calibration before releasing it for first-time use. Results show the values obtained in calibration of apheresis equipment, relating to the MNC protocol (removal of mononuclear cells), the pressure of access, and return pressure.
\end{abstract}

Keywords - Qualification of Incorporation, Biomedical Equipment, Calibration of Apheresis Machines.

Copyright (C) 2021. This is an open-access article distributed under the terms of the Creative Commons Attribution License (CC BY): Creative Commons - Attribution 4.0 International - CC BY 4.0. The use, distribution or reproduction in other forums is permitted, provided the original author(s) and the copyright owner(s) are credited and that the original publication in this journal is cited, in accordance with accepted academic practice. No use, distribution or reproduction is permitted which does not comply with these terms.

\section{INTRODUCTION}

Among the human pathologies are hematological diseases, immunodeficiency, genetic diseases and some tumors such as from breast cancer. One of the available treatments is donor (autologous) and donor (allogeneic) donor transplantation of peripheral blood progenitor cells. These cells, classified as CD34 +, have a high capacity for self-renewal and proliferative potential, which makes it possible to differentiate them into progenitor cells from all blood strains and to reconstitute the population from a single cell hematopoietic. Also called a blood stem cell. They comprise $0.05 \%$ to $0.1 \%$ of circulating human bone marrow hematopoietic cells. ${ }^{1,2}$ For collection and treatment in this invasive and safe procedure, a cell separator, called the apheresis machine, is used, which in Greek means separation. Apheresis therapy is the removal of one or more components of a person's whole blood. One of the most important steps in the process is the introduction of a sufficient amount of anticoagulant sufficient to prevent blood components from clotting or clumping together when they are processed through the apheresis device. The anticoagulant flow rate cannot be high, to avoid adverse reactions in the donor/patient. Depending on the amount of anticoagulant returned, you can generate physical symptoms such as tingling in the extremities until the potential damage to the donor/ patient. ${ }^{3}$ The apheresis equipment can be used to remove plasma (plasmapheresis), leukocytes (leukapheresis/ lymphocyteapheresis), platelets (thrombocyte-apheresis centre) or the red cells (erythrocyte apheresis). ${ }^{4}$

The apheresis machine performs the separation of peripheral blood and blood products through a technology that utilizes centrifugal effect forces. Cells with higher densities are targeted at specific layers, where they can be identified and collected by a cardiopulmonary bypass induced by the equipment itself. The basic steps of apheresis, are the removal of whole blood from a donor 
or patient, separating blood components, plasma retention, or one of its cellular components and returning the remaining elements to the donor or patient. ${ }^{5}$ The principle of operation of this equipment is shown in Figures $1 \mathrm{~A}$ and $1 \mathrm{~B} .{ }^{6}$ These centrifugal forces act on only a small portion of the blood, causing the separation of blood elements, called apheresis.

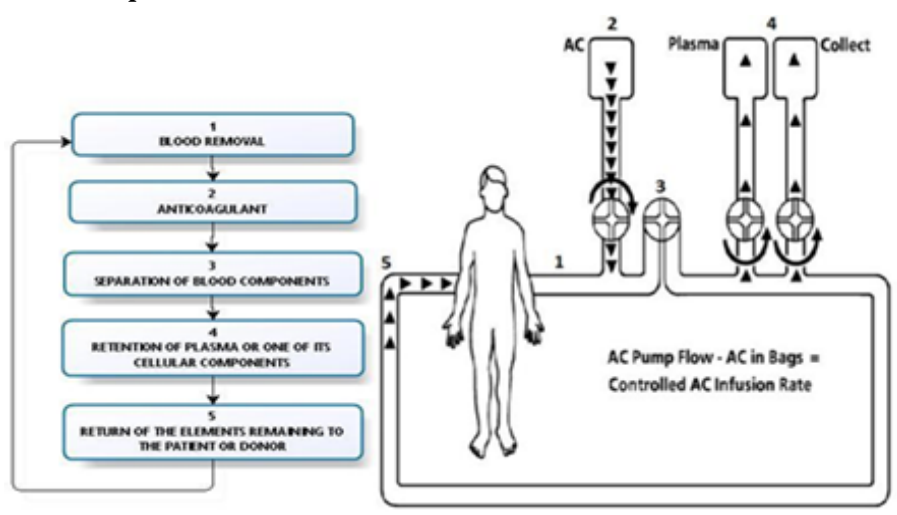

FIGURE 1. Apheresis circuit.

After the end of the cycle, which takes around three to five hours, the desired component is directed into a collection bag. The apheresis machine procedure is initiated by a physician who performs the programming of the parameters based on the mononuclear cells removalMNC protocol. (The protocol's calculation is based on the amount of hematocrit collected from autologous or allogeneic donator, on the day of the procedure. ${ }^{7}$ ) The physician keeps up with the process and monitors the physical state of the patient. The physician inputs the age, sex, and weight of the patient or donor and also assesses the need to change the length time or flow rate. At the end of processing, it is possible to collect the plasma cells, platelets, lymphocytes, granulocyte, and erythrocyte as needed. Figure 2 demonstrates the specific blood cell densities. ${ }^{8}$

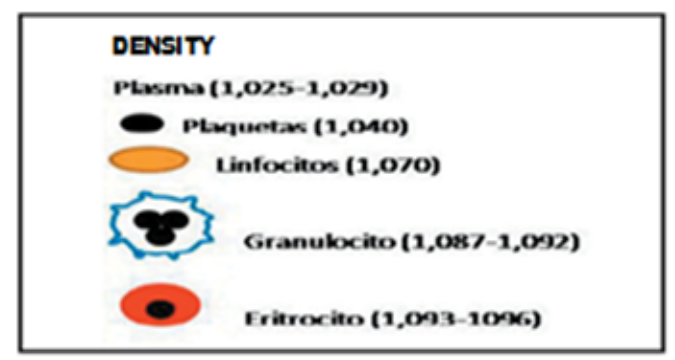

FIGURE 2. Demonstration of specific cell densities.
Considering the given relevance, criticality, and care necessary in the method of separation of cells by apheresis, we need to understand how testing with this equipment is performed. When evaluating the methods of certification effectiveness of operating and the results of the procedure performed by the apheresis machine, it was verified that an item of Brazilian Resolution number $57,{ }^{9}$ called calibration is not necessarily being performed in a systematized way. This evaluation was done with the manufacturer of the equipment, specialists, and general research. It is critical to confirm the proper functioning of apheresis equipment using calibration, before releasing use throughout the course of its lifecycle. This paper aims to propose and demonstrate a method of accomplishing the qualification of apheresis equipment through calibration, in addition to the usual quantitative testing, before it is released for use.

\section{METHOD}

\section{Search}

During this process, we checked for quality control regulations for this equipment and standards relevant to its use. It was requested for the equipment manufacturer to provide the operating limits and tolerances of pressure and volume measured parameters as well as procedures to confirm conformity of post-factory output specification. It was verified in article 11 of the Brazilian Resolution 57/2010 that "The Hematology services must have compatible equipment activities and establish a program that includes initial validation, qualification, calibration, preventive and corrective maintenance of equipment and instruments, keeping their schedules and records."

When evaluating the methods of certification effectiveness for operation and results of the machine, it was found that the method used is often a six-month check to compare technical specifications to actual physical parameters. The parameters evaluated are those relating to access pressure, back pressure, pressure leaks, pressure sensors, rotation of centrifugal, circulation pumps, red sensor, and the digital conversion of these parameters.

According to information from the medical care specialists in the subject, normally the form of verification of the performance of the machine is the analysis of 
the count of the blood products and blood products of patients, post-procedure. In this case, when the quality of processing is not adequate, there is a need to inform the patient of the need to perform a new procedure and consequently expose themselves again. Figure 3 has the flow method, with job steps.

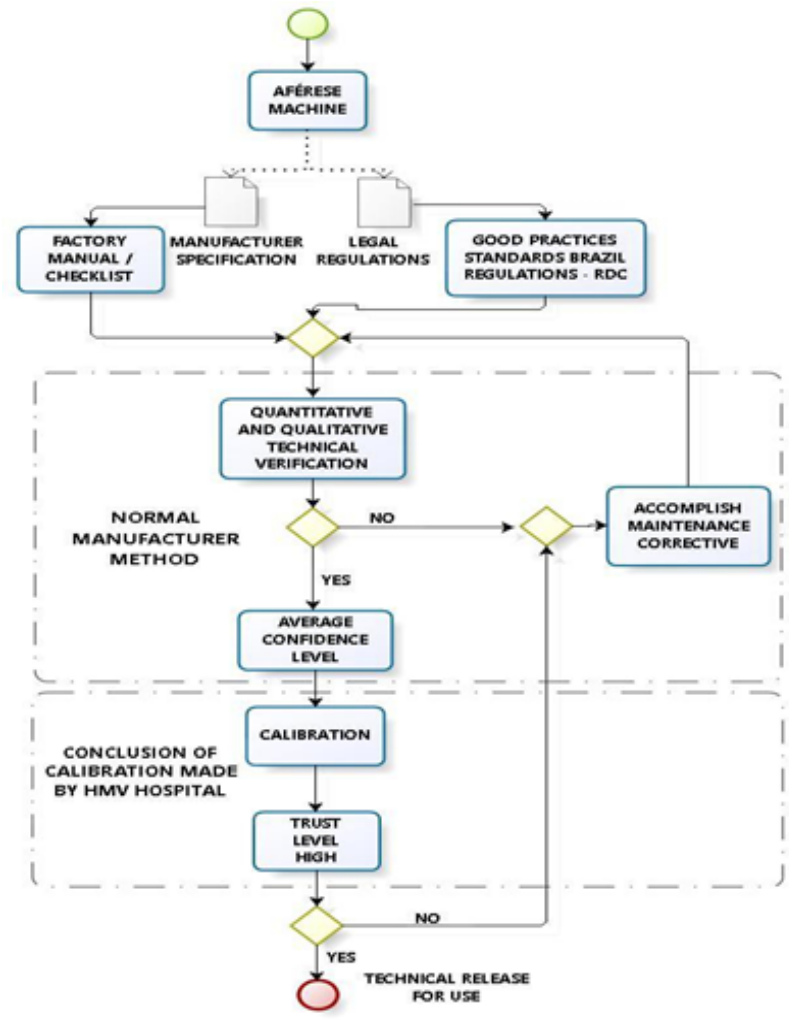

FIGURE 3. The flow method, with job steps.

Figure 3 shows the proposed inclusion of equipment calibration step as a way to raise the level of confidence of apheresis.

\section{RESULTS}

\section{Calibration Planning}

A qualified company was hired to perform the calibration which evaluated the uncertainties involved and the standard deviations. This was done in conjunction with hospital technicians who assisted in this activity by providing access to the service equipment.

The following parameters were evaluated: pressure (mmHg), back pressure (mmHg), and Protocol MNC in volume $(\mathrm{mL})$. The calibration method for measuring the volume was to measure the volume by weighing the liquid by time. For pressure measurement was performed compared to the default. The materials used for calibration were: digital scale, digital Timer and Pressure Analyzer.

The calibration results were presented according to the following Table 1.

TABLE 1. Presentation of the Measured Data for the Equipment: a) MNC protocol collection bag, b) access pressure and c) back pressure

\section{a) Apheresis - MNC Protocol - Collection Bag}

\begin{tabular}{|l|c|c|c|l|c|}
\hline $\begin{array}{l}\text { Set. } \\
\text { Volume } \\
(\mathbf{m L})\end{array}$ & $\begin{array}{l}\text { Value } \\
\text { Measured }\end{array}$ & $\begin{array}{l}\text { Average } \\
\text { Error }\end{array}$ & Uncertainty & $\begin{array}{l}\text { Total } \\
\text { Error }\end{array}$ & $\begin{array}{l}\text { Tolerance } \\
\text { Limits }\end{array}$ \\
\hline 175 & 179,10 & 4,10 & $\pm 0,01$ & $|4,11|$ & $6 \%$ \\
\hline
\end{tabular}

b) Apheresis - MNC Protocol - Access Pressure

\begin{tabular}{|l|l|l|l|l|l|}
\hline $\begin{array}{l}\text { Set. } \\
\text { Pressure } \\
(\mathbf{m m H g})\end{array}$ & $\begin{array}{l}\text { Value } \\
\text { Measured }\end{array}$ & $\begin{array}{l}\text { Average } \\
\text { Error }\end{array}$ & Uncertainty & $\begin{array}{l}\text { Total } \\
\text { Error }\end{array}$ & $\begin{array}{l}\text { Tolerance } \\
\text { Limits }\end{array}$ \\
\hline-265 & $-270,00$ & $-5,00$ & $\pm 0,01$ & $|5,01|$ & $12 \%$ \\
\hline-150 & $-147,10$ & 3,00 & $\pm 0,01$ & $|3,01|$ & $12 \%$ \\
\hline-50 & $-54,00$ & $-4,00$ & $\pm 0,01$ & $|4,01|$ & $12 \%$ \\
\hline
\end{tabular}

c) Apheresis - MNC Protocol - Return Pressure

\begin{tabular}{|c|c|c|c|c|c|}
\hline $\begin{array}{l}\text { Set. } \\
\text { Pressure } \\
(\mathbf{m m H g})\end{array}$ & $\begin{array}{l}\text { Value } \\
\text { Measured }\end{array}$ & $\begin{array}{l}\text { Average } \\
\text { Error }\end{array}$ & Uncertainty & $\begin{array}{l}\text { Total } \\
\text { Error }\end{array}$ & $\begin{array}{l}\text { Tolerance } \\
\text { Limits }\end{array}$ \\
\hline 52 & 50,00 & $-2,00$ & $\pm 0,01$ & $|2,01|$ & $12 \%$ \\
\hline 254 & 256,00 & 2,00 & $\pm 0,01$ & $|2,01|$ & $12 \%$ \\
\hline 403 & 408,00 & 5,00 & $\pm 0,01$ & $|5,01|$ & $12 \%$ \\
\hline
\end{tabular}

In this way, the calibration procedure was added to the quantitative tests that were conducted for this type of equipment and complemented the proposed qualifying procedure apheresis equipment before release technique to use.

\section{Performing Verification Technician}

Among the quantitative tests also performed are: checking the battery voltage of master boards; endurance tests 
of the protection earth leakage current; verification of AC and DC voltages; verification and calibration of pressure sensors; functional check of the RBC detector; verification of pump rotation; and simulation with saline.

\section{CONCLUSIONS}

Evidence shows that the parameters compared were calibrated within the tolerances stated by the manufacturer. It was noted also that all measurements fell between the variations set and measured (even if within the range of tolerance). In this way, there may be situations where the parameters are very close to the tolerance allowed or even outside of it. Also, we can apply techniques of probability (considering the uncertainties of measurement) to evaluate whether the value measured is within the maximum allowable limit.

Another point to assess is the type of protocols and tests that must be performed in this equipment so that they can reflect, in the most appropriate way, the effectiveness of the process of blood cell separation carried out by the machine.

Considering the details above, there is a need to consolidate criteria and do a greater scope of tests and calibrations on apheresis equipment to avoid initial or routine use of equipment that has not been calibrated. This may help ensure that the equipment performs properly and thus avoid the risk of errors.

\section{CONFLICT OF INTEREST}

The authors declare that they have no conflict of interest.

\section{REFERENCES}

1. Quesenberry PJ, Colvin GA, Beutler E, et al. Williams Hematology, North America 2001;6:153-74.

2. Zerlotti HWG, Noronha JFA. Identification of hematopoietic stem cells: conventional flow cytometry versus automated hematology counter view. Braz Hematol Hemother 2003;169-72.

3. Grimm DJ. Apheresis system with anticoagulant flow. US: Baxter; 2005.

4. Marikar A, Tatsui NH. Therapeutic Aféreses. Cap 2001;21:257-71.

5. Hlavinka DJ, Felt TJ. Centrifugal separation method for separating fluid components US, Google Patents, Gambro; 1999.

6. Gambro. Model Cobe Spectra. Introduction to User Manual. Rev. E; 2001.

7. Schmaldienst S, Goldammer A, Derfler K, et al. Location of the extracorporeal circuit anticoagulation with heparin neutralization with protamine by the company and during immune ergatterte. Division of Hematology and Blood Coagulation, University of Vienna, 2000;September 36:490-97.

8. Octavian CJ. Serological evaluation for infectious diseases transmitted through blood transfusion in blood recipients, General Hospital of Palmas, Brazil dissertation; 2015.

9. ANVISA. The National Health Surveillance Agency of the Brazilian. Resolution RDC 57 Collegiate Board of Directors of the Brazilian, No. 57. 2010. Available at https://portal.anvisa.gov.br. 